\title{
Tidal mixing modulation of sea-surface temperature and diatom abundance in Southern California
}

\author{
Alejandro J. Souza ${ }^{\mathrm{a}, *}$, Jesús Pineda ${ }^{\mathrm{b}}$ \\ a Proudman Oceanographic Laboratory, Bidston Observatory, Bidston Hill, Prenton CH43 7RA, UK \\ ${ }^{\mathrm{b}}$ Biology Department, Woods Hole Oceanographic Institution, Woods Hole MA 02543, USA
}

Received 8 January 1999; received in revised form 24 November 1999; accepted 22 September 2000

\begin{abstract}
In the Southern California Bight a clear seasonal cycle in temperature and diatom abundance is observed, with maximum temperatures in summer and maximum diatom abundance in spring, decreasing in summer. Within this seasonal cycle of temperature and diatom abundance, there is a weak fortnightly temperature variability. Here, we show that diatom abundance has lunar as well as seasonal variability, with the highest abundance corresponding to the coldest days within the lunar cycle. This suggests that at least part of the temperature and diatom abundance variability may be due to bottom tidal mixing. To explore the effect of tidal mixing and tidal straining on the control of the thermal structure of the water column in the Southern California region, a one-dimensional, hydrodynamic numerical model is used. The model is successful in explaining the seasonal cycle in temperature and partially explains the fortnightly and monthly variability in temperature. The observed temperature minimum shows a lag of about 2-3 days, when compared with model results. This lag is probably due to the fact that the model does not include the effect of internal waves, which will be an extra source of mixing and may have an advective effect that will modify the water-column structure and the diatom distribution. (C) 2001 Elsevier Science Ltd. All rights reserved.
\end{abstract}

Keywords: Sea-surface temperature; Diatom abundance; Tidal mixing modulation

\section{Introduction}

The fortnightly periodicity in sea-surface temperature (SST) in the nearshore Southern California Bight (SCB, Fig. 1) has been explained in terms of advection, generated by internal tidal bores (Pineda, 1991, 1995).

\footnotetext{
*Corresponding author. Tel.: + 44-151-653-8633; fax: 44-151-653-6269.

E-mail address: ajso@pol.ac.uk (A.J. Souza).
} 


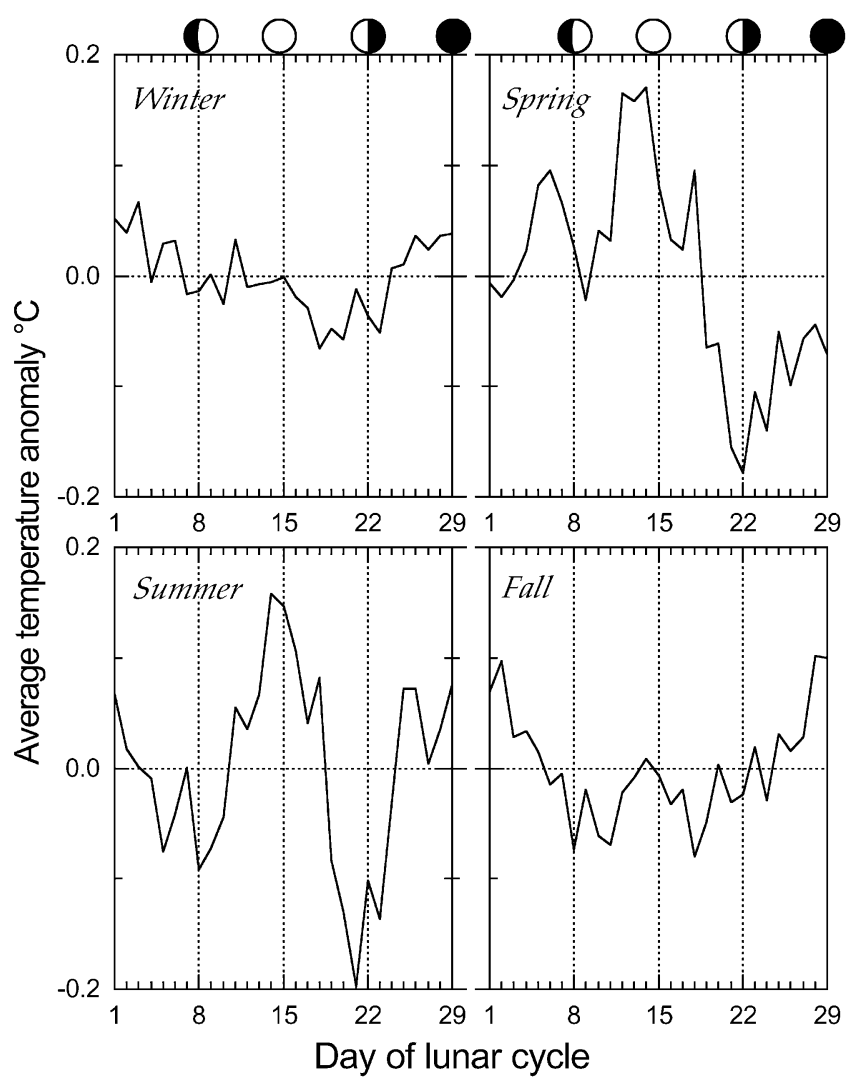

Fig. 1. Mean surface water temperature anomaly for each day of the lunar cycle averaged for Southern California shore stations Santa Monica, Balboa, San Clemente, Oceanside, and La Jolla (Scripps Institution of Oceanography). Mean surface water temperature anomaly for each shore station was obtained by: (1) subtracting each daily datum to the day of the year average of the corresponding station; (2) fitting each anomaly to a day of the lunar cycle (29 units) and to a calendar season; and (3) averaging by day of the lunar cycle and season (see Balch, 1986; Pineda, 1995). Mean surface water temperature anomaly for Southern California shore stations were then averaged. In each station, surface water temperature is sampled daily at the offshore lighthouses, beaches or piers, and time-series length at stations range from 18 to 68 years. For exact locations, see Scripps-Institution-of-Oceanography (1989).

The bores occur in two phases in the SCB - the cold phase is characterised by onshore advection of a cold-water bore (Cairns, 1967; Winant, 1974), which displaces warm water offshore, and creates an imbalance in hydrostatic pressure between denser inshore water and lighter offshore water. This phase is followed by the warm phase, where the inshore water recedes offshore due to its greater density, whilst a warm bore returns (Pineda, 1994). Nearshore bores occur in groups of two to nine events in spring and summer, when the water column is well stratified; when these occur, the surface water temperature drops. These events have semi-diurnal or diurnal periodicity. The cold phase can explain the onshore transport of water column planktonic invertebrate and fish larvae (Pineda, 1991; Leichter et al., 1998), whilst the warm phase explains the transport of both surface and water column larval taxa (Pineda, 1994, 1999). Nutrient-rich waters and phytoplankton can also be transported shoreward. The occurrence of 
the bores at tidal periodicity (e.g. semi-diurnal), the drop in surface water temperature during groups of events, and the settlement of invertebrates peaking at lunar periodicity has led Pineda (1995) to suggest that the fortnightly periodicity in SST in Southern California could be explained by a fortnightly cycle in internal tidal bores, an idea consistent with a potential fortnightly cycle in the internal tide (e.g. Cairns, 1967).

However, the fact that the temperature reduction between 0.25 and $1{ }^{\circ} \mathrm{C}$ is maintained for several days actually suggests that this fortnightly variability might be due to mixing, either due to internal solitons or to bottom tidal stirring. Balch (1986) and Pineda (1995) discarded the idea that bottom tidal mixing was directly responsible for the cooling and mixing at the sea surface in their study area, because the most negative anomalies lagged several days after spring tides. Balch (1986) observed a lag of 5-6 days for annual-averaged anomalies, whilst Pineda observed a lag of 8-13 days after a new moon $(\circ)$ and 6-11 days after a full moon $(\bullet)$, for seasonally averaged anomalies. It was argued that a tidal mixing mechanism would produce colder temperatures closer to spring tides. Pineda (1995) argued also against tidal mixing, based on the supposition that tidal mixing could not explain that at several stations there were two cycles of water temperature anomaly per lunar cycle in summer, but only one in spring.

It has been observed however, that in cases of tidal mixing fronts, there is a lag of approximately 3-4 days between the currents and temperature. The maximum negative anomaly is expected to occur approximately 3 to 4 days after spring tides, with the maximum positive anomaly 3 to 4 days after neap tides (Simpson and Bowers, 1981). Sharples and Simpson (1996) suggest that the reason for this lag is the presence of thermal inertia, as stratification progresses into mixed water towards neap tides, together with the need to re-mix stored buoyancy as the stratified region is eroded towards spring tide. Hence, the lag between the spring tide and mixing is due mainly to more stored potential energy at first requiring more mixing energy. On the other hand, the presence of only one period of a negative temperature anomaly during a lunar cycle could be due to an $\mathrm{N}_{2}$ modulation of the spring-neaps cycle (Sharples and Simpson, 1996). Therefore, it is unclear whether bottom mixing could explain some of the fortnightly phenomena observed by Balch (1986) and Pineda (1995). Furthermore, the fortnightly variability in mixing will bring a fortnightly variability in the availability of nutrients, as nutrients are mixed upwards from the bottom layer to the surface. With an increase in the availability of nutrients, a phytoplankton bloom may develop. Obviously, there would be a lag between the time the nutrients become available and the time the phytoplankton bloom develops; this could vary between 3 days and half a spring-neaps cycle, depending on the phytoplankton species.

Similar to the internal bores, tidal straining could be responsible for the semi-diurnal variability in temperature and for plankton and nutrient cross-shore transport. The interaction of the density gradients, with the differential advection resulting from the sheared velocity profile, will generate an alternation between a stratified warm period and a mixed cold period. During the ebb, the faster surface tidal currents will push the warmer coastal waters offshore, generating a warm surface layer. Conversely, during the flood, colder oceanic waters will be advected by the faster surface tidal currents. However, because the colder oceanic waters are denser than the underlying coastal warm waters, the water column would be unstable, resulting in convective mixing which will generate a cooler more homogeneous water column (Simpson et al., 1990). This semi-diurnal differential advection could be responsible also for the onshore and offshore larval transport, especially if combined with vertical larval migration. 
A classical theme in marine ecology is how hydrodynamic phenomena impose their temporal and spatial scales on ecological systems (Haury et al., 1978). Knowledge of the temporal and spatial scales of variability in ecological phenomena is important in identifying the underlying forcing mechanisms. Ecological phenomena such as phytoplankton abundance sometimes exhibit lunar periodicity. Proximate explanations, to account for this periodicity, include "extrinsic" hydrodynamic forcing and "intrinsic" individual behaviour. These include differential phytoplankton responses due to changes in stratification in the spring to neap cycle, with associated variability in nutrient input due to tidal mixing (Balch, 1986; Demers et al., 1986). In cases where there is an ecological response to the lunar cycle, the question arises as to whether the response is due to extrinsic hydrodynamic forcing or intrinsic behaviour. If the ecological response is due to hydrodynamics, it is obviously important to identify the forcing mechanism, as different forcing may have different ecological consequences.

In this paper, we show that a simple one-dimensional numerical hydrodynamic model explains some aspects of the fortnightly variability in sea-surface temperature observed on the West Coast of the US. We then discuss previous temperature observations and contrast them with model results, and propose that periodicity in SST is related to bottom mixing. We also present evidence of lunar variability of diatom abundance and discuss the potential effects of tidal mixing.

\section{Temperature observations}

Water temperature has been sampled at the end of the Scripps Institution of Oceanography (SIO) Pier, in Southern California, since $\sim 1920$. Fig. 2 shows the 7-day running mean filtered dayof-the-year average surface (1920-1989) and bottom (1927-1989) water temperature. As has been observed before (e.g. Allen, 1941), there is a seasonal cycle, with the lowest temperatures in winter and the highest temperatures in summer. Within this seasonal cycle of temperature, there is a fortnightly/monthly cycle of variability (e.g. Balch, 1986; Pineda, 1991, 1995) with cooler

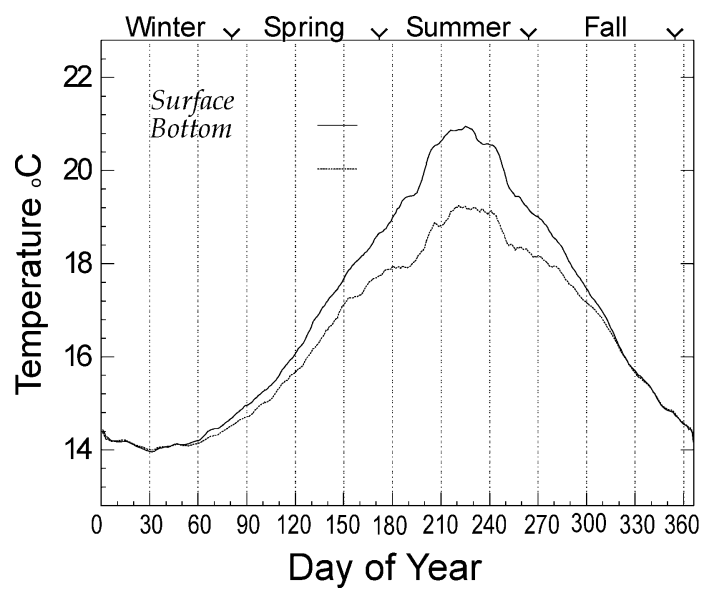

Fig. 2. Mean daily surface (1920-1989) and bottom (1927-1989) water temperatures at the Scripps Institution of Oceanography (SIO) pier. Average filtered with a 7-point running mean filter. 
temperatures around days $8(\mathbf{O})$ and $22(\mathbf{0})$ of the lunar cycle, as shown in Fig. 1. In Southern California, the cycle is weak and fortnightly periodicity is often absent in observed time-series (Pineda, 1995).

\section{Modelling mixing in the Southern California Bight: a one-dimensional model}

In order to test the hypothesis that the fortnightly cooling is related to bottom tidal mixing, a modified version of the Simpson and Sharples (1992) model has been used. The model uses an explicit scheme to integrate the equations of motion:

$$
\begin{aligned}
& \frac{\partial u}{\partial t}=-\frac{1 \partial P}{\rho \partial x}+f v+\frac{\partial}{\partial z}\left(N_{z} \frac{\partial u}{\partial z}\right), \\
& \frac{\partial v}{\partial t}=-\frac{1}{\rho} \frac{\partial P}{\partial y}-f u+\frac{\partial}{\partial z}\left(N_{z} \frac{\partial v}{\partial z}\right)
\end{aligned}
$$

with $x$ and $y$ positive in the east and north directions, respectively, and $z$ increasing positively from the seabed. The second term on the right is the Coriolis forcing and the third term is the effect of friction between the layers in transporting momentum vertically through the water column, with $N_{z}$ the coefficient of vertical eddy viscosity. The pressure gradient terms in Eqs. (1) and (2) are given by

$$
\frac{1}{\rho} \frac{\partial P}{\partial x}=g\left(\frac{\partial \eta}{\partial x}\right)_{\text {tidal }}+g \frac{\partial \bar{\eta}}{\partial x}+\frac{g}{\rho}(h-z) \frac{\partial \rho}{\partial x}
$$

and, similarly, for the $y$ component. The first term on the right-hand side of Eq. (3) is the tidal slopes, calculated using Schwiderski (1980) tidal data for $\mathrm{K}_{1}, \mathrm{~K}_{2}, \mathrm{M}_{2}, \mathrm{M}_{\mathrm{f}}, \mathrm{N}_{2}, \mathrm{O}_{1}, \mathrm{Q}_{1}$ and $\mathrm{S}_{2}$. The second two terms represent the effect of a depth-invariant horizontal density gradient in setting up a mean surface slope and driving a depth-dependent density circulation. Calculation of the mean surface slope is achieved by specifying a zero net flow condition in the cross-shore direction, in such a way that

$$
\frac{\partial \bar{\eta}}{\partial x}=\gamma \frac{h}{\rho} \frac{\partial \rho}{\partial x},
$$

where the parameter $\gamma$ is chosen to make the net cross-shore transport equal zero. Boundary conditions for the momentum equations are a quadratic stress law at the bottom and wind stress at the sea surface. The horizontal advection and vertical diffusion of temperature at each level is controlled by

$$
\frac{\partial T}{\partial t}=-u \frac{\partial T}{\partial x}+\frac{\partial}{\partial z}\left(K_{z} \frac{\partial T}{\partial z}\right)
$$

where $\partial T / \partial x$ are the horizontal temperature gradients, assumed depth-independent and used as a tuning parameter to obtain the correct annual cycle in stratification. $K_{z}$ is the coefficient of vertical eddy diffusivity, with no heat flux through the seabed. Surface heating is specified in terms of Edinger et al. (1968) formulation, using climatological data from Berliand (1960) and from the 
Marine Climatic Atlas of the World (United-States-Navy, 1992). This formulation calculates the surface heat fluxes, considering solar irradiance as an input and back radiation related to humidity, surface temperature and wind speed as an output.

A Mellor-Yamada level-2 turbulence closure scheme is used to calculate vertical profiles of $N_{z}$ and $K_{z}$ as functions of local stability via

$$
N_{z}=S_{M} l q, \quad K_{z}=S_{H} l q,
$$

where $q^{2}$ is the turbulent kinetic energy, $l$ is a mixing length and $S_{M}$ and $S_{H}$ are stability functions, which depend on the local gradient Richardson number (for details, see Mellor and Yamada, 1982). The model produces a seasonal cycle in temperature (Fig. 3), which is in agreement with the average in Fig 2. Non-averaged observations of temperature, however, are much more variable than the results produced by the model (e.g. compare Fig. 7 of Balch's (1986)with our Fig. 3), as the model uses smooth climatological forcing.

To compare the model results with the observations of Balch (1986) and Pineda (1995), it is necessary to observe how our spring-neap cycle relates to the lunar cycle. For this, as well as including the lunar phases in our figures, we have calculated the time of maximum tidal ranges relative to new or full moon. This lag is called the age of the tide, and it can readily be calculated following Pugh (1987) as

$$
T_{a}=\frac{\phi_{M_{2}}-\phi_{S_{2}}}{\omega_{M_{2}}-\omega_{S_{2}}}
$$

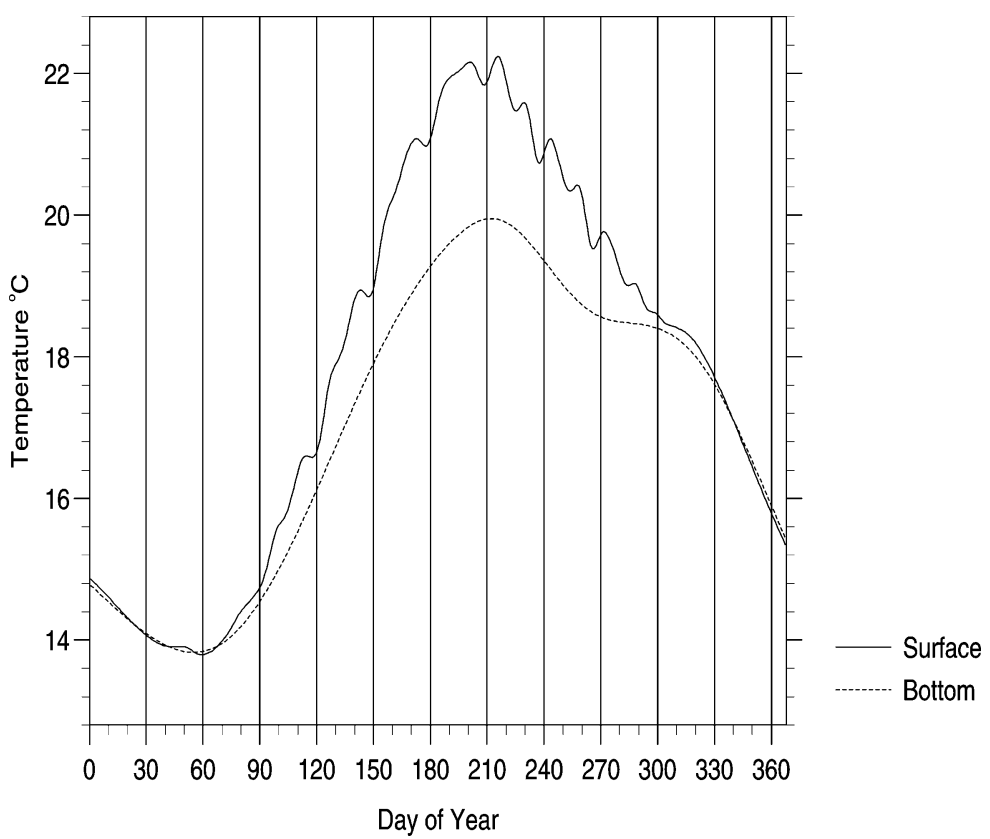

Fig. 3. Seasonal cycle of temperature as simulated by the model, for a location near SIO Pier. Continuous line is the surface while the dashed line is the bottom grid point. 
where $\omega_{M 2}, \phi_{M 2}$ and $\omega_{S 2}, \phi_{S 2}$ are the frequency and phase for the $\mathrm{M}_{2}$ and $\mathrm{S}_{2}$ tidal constituents, respectively. Fig. 4 shows that the age of the tide has a value ranging between $\pm 12 \mathrm{~h}$ in the entire $\mathrm{SCB}$, so that we can compare directly the model results using tidal elevation with the results presented by Pineda (1995). Other constituents such as $\mathrm{N}_{2}$ and $\mathrm{M}_{4}$ can modify this expression and, indeed, it can be observed in Fig. 5 that, at some times, there is a larger lag; however, for general purposes, this should be sufficient.

Figs. 5 and 6 show the model results during the stratified season for two different years, 1985 and 1995. In Figs. 5a and 6a we can clearly appreciate a fortnightly cycle in stratification, with $\Delta T$ values ranging between 0 and about $2.5^{\circ} \mathrm{C}$. The tidal mixing energy has a maximum value of about $8.5 \mu \mathrm{W} \mathrm{m}^{-3}$ (Figs. $5 \mathrm{~b}$ and $6 \mathrm{~b}$ ). There are two minima $\Delta T$, corresponding to maximum mixing, in every lunar cycle, one after new moon and the other after full moon. For every lunar cycle, the minimum in $\Delta T$ and maximum in mixing occur after a new moon (•) in 1985, but after a full moon (O) in 1995. As in any other region where bottom tidal mixing is important, the stirring leads slightly the period of reduced stratification. Even more interesting is that the period of maximum tidal mixing lags the spring period (period of maximum tidal range), by another 2

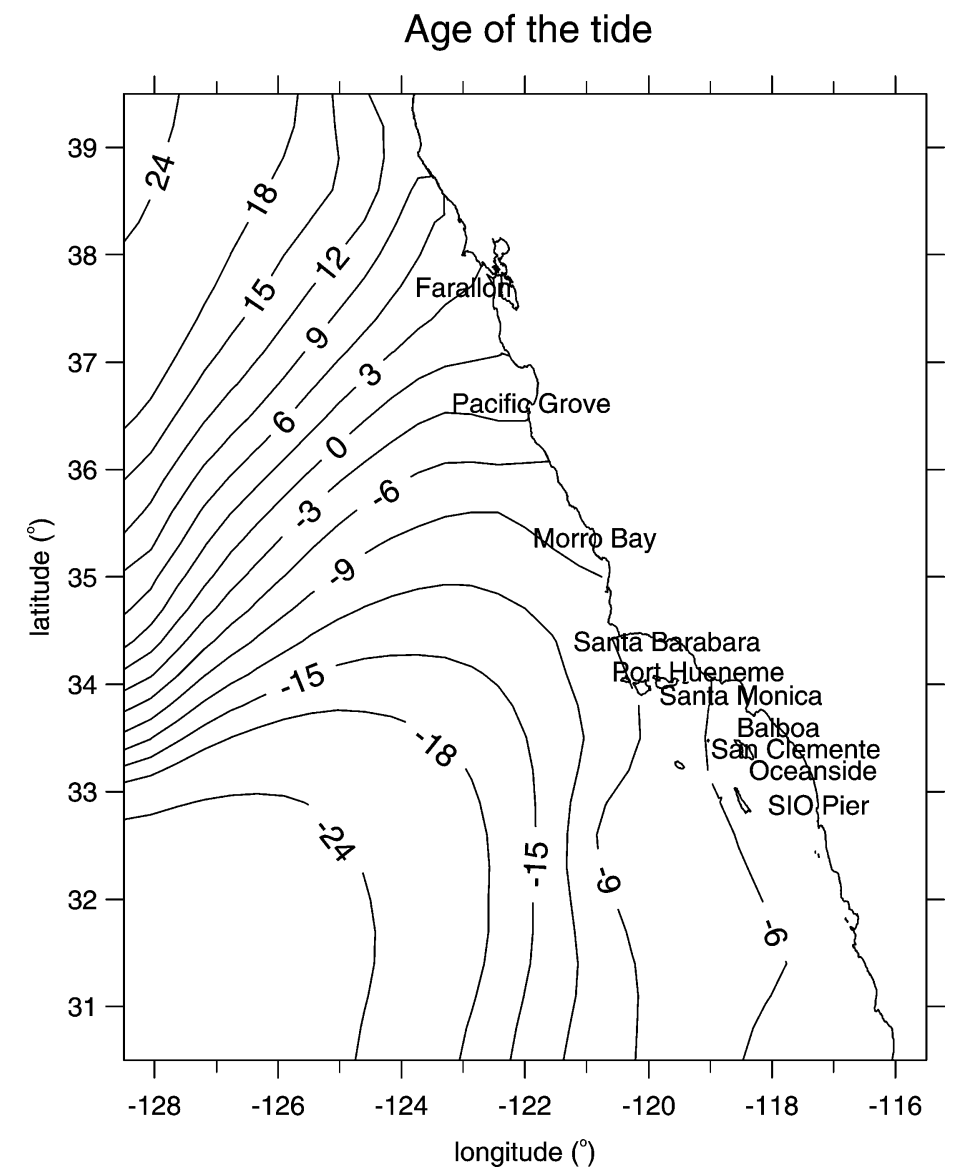

Fig. 4. Age of the tide (in h) for the Southern California Bight, using Schwiderski (1980) data. 


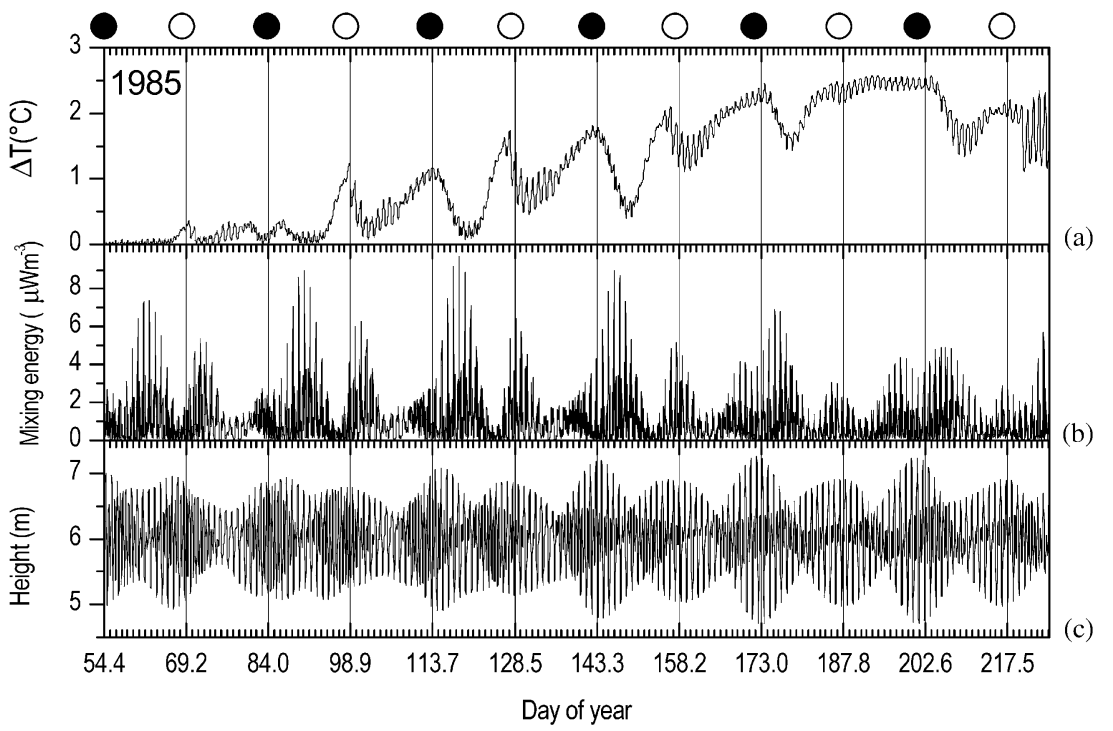

Fig. 5. Model results for a simulation of a seasonal cycle at a point near SIO Pier, in 1985: (a) surface-bottom temperature difference; (b) tidal mixing energy calculated using Simpson and Bowers (1981) efficiencies; (c) sea-surface elevation.

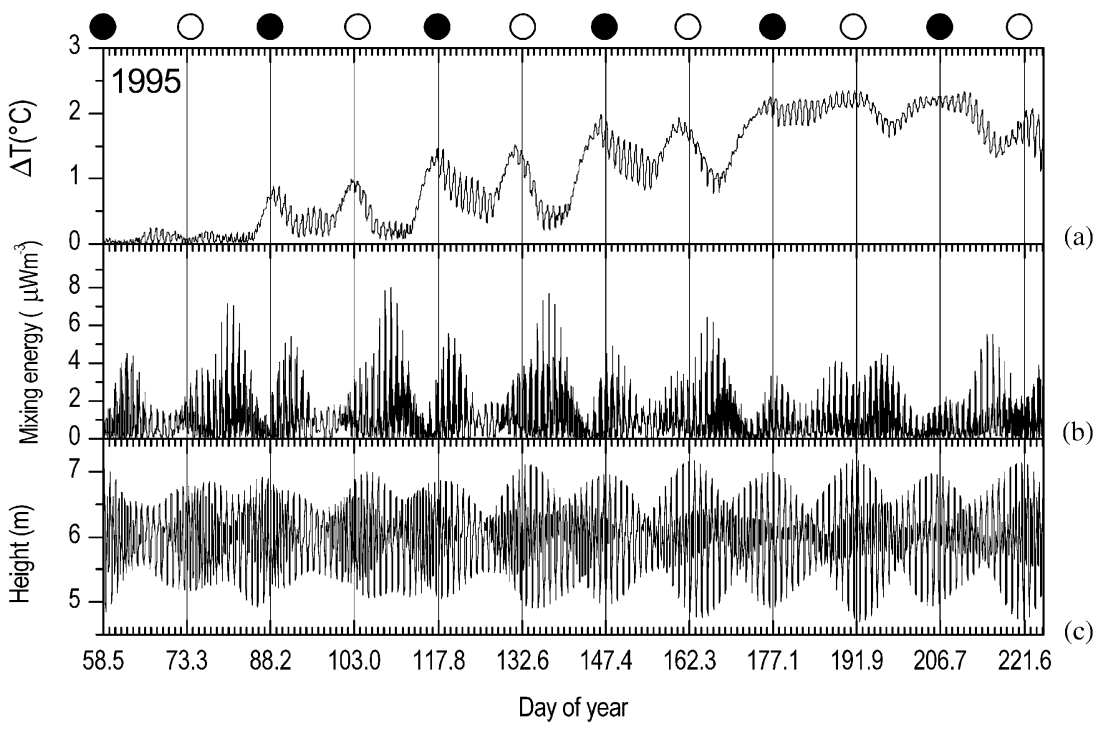

Fig. 6. Same as Fig. 5, but for 1995.

days. This will give the total lag, between springs (new/full moon) and the period when the temperature anomaly is more negative, to be between 4 and 6 days. Another interesting feature is the strong semi-diurnal variability in temperature, with changes in $\Delta T$ of about $1.5^{\circ} \mathrm{C}$ within $12 \mathrm{~h}$. This variability is due to the interaction of tidal straining with the horizontal temperature 


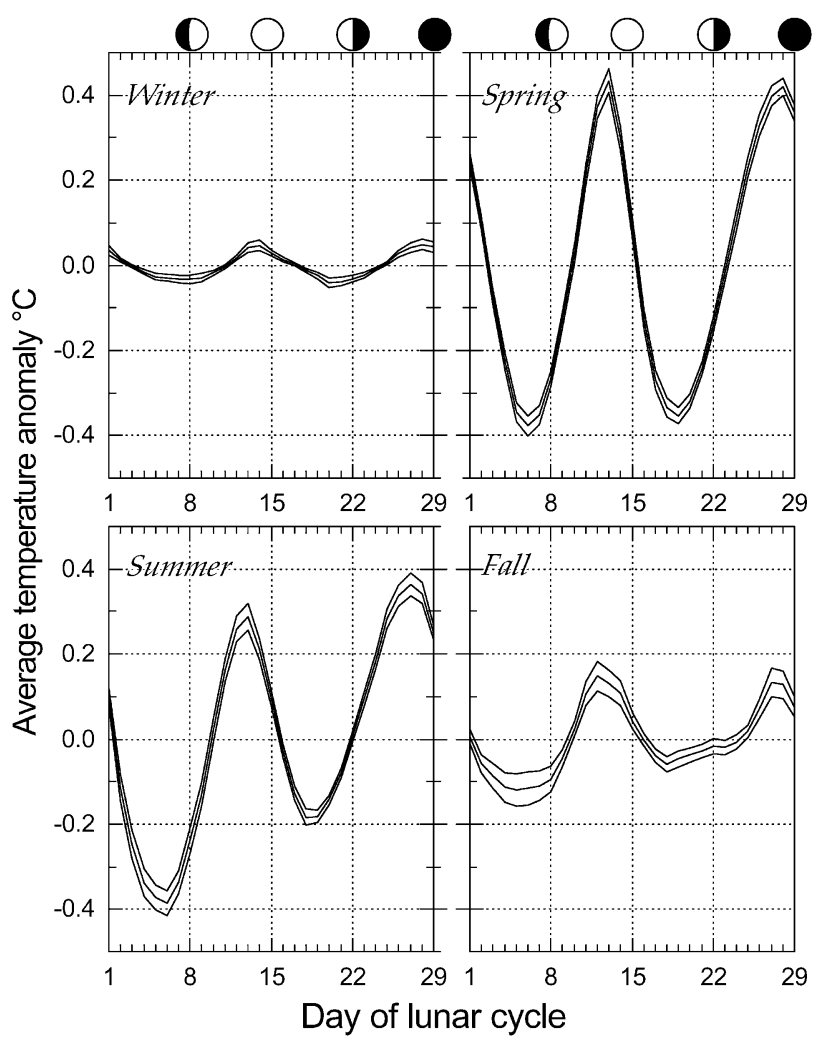

Fig. 7. Mean and $+1 \mathrm{SE}$ of model mean surface water temperature anomalies for day of lunar cycle and season.

gradients. The barotropic tidal velocities are sheared, due to the effect of bottom friction; this will generate a differential advection of the temperature field, generating stratification, as the surface water is advected further away than the bottom water (Simpson et al., 1990).

The model was run for 13 years and the anomalies by season and by day of lunar cycle were obtained by subtracting each daily observation form the day-of-the-year average of 13 years and partitioning the time-series by season and by day of lunar cycle. Fig. 7 shows lunar variability in all the seasons. Winter and autumn anomaly amplitudes were relatively small. The fortnightly variability in spring and summer show the largest negative amplitude, coinciding with days 6 and 19 of lunar cycle. The summer's first-quarter negative anomaly was larger than the third quarter's, probably due to changes in $\mathrm{N}_{2}$ tidal modulation.

\section{Diatom abundance}

The phenomenon that temperature is predictably lowest on some days of the lunar cycle suggests a correlation with the lunar cycle in phytoplankton abundance. To explore this idea, we used a phytoplankton time-series. Allen and his associates sampled phytoplankton from 1920 to 1939 at the end of the SIO pier (depth ca. $6 \mathrm{~m}$ ). Allen reported both dinoflagellate and diatom 
abundance, but here we only consider the diatoms. Sampling frequency was daily with the exception of holidays (and Sundays, starting in 1924). Allen divided the year into 52 intervals ('weeks' (Allen, 1927)) and reported averages for the end of each 7 day interval, where all the years start with January 1 as Day 1 of Interval 1. Before 1930, 351 of water were sampled and filtered through a \#25 mesh (30-100 $\mu \mathrm{m}$, in new mesh sizes) (Allen, 1930) Starting in 1930, filtration was replaced by a settling technique (Allen, 1930, 1941), where a fraction of the organisms that settled from a 1-1 sample were counted in a Sedgwick-Rafter counter. This change in technique correlated with a striking increase in the number of dinoflagellates, whereas diatom abundance changed relatively less (Allen, 1930). Allen's diatom data used in this contribution were total number of diatoms per litre (cells/1), taken from Tont (1986).

To test the hypothesis that diatom abundance was highest during the days of the lunar cycle where temperature is lowest, each weekly diatom abundance value was fitted to a lunar cycle day. Days of the lunar cycle were obtained as described by Balch (1986) and Pineda (1995). The representative date of the weekly average was chosen to be the centre of the week. For example, if the value read "Week ending January 7" in Allen's files, it was taken to represent January 4. The corresponding day of lunar cycle for January 4 was then obtained. Since Sundays were not sampled in most years, most averages represent 6 days. For each year, Sunday occurred on a fixed position in Allen's weeks (e.g. day 6 in 1924). This causes a small bias in obtaining the average for mid-week because days 5-7 are under represented. Since, through the years, Sundays do not tend to consistently correspond to same day of Allen's week, Sunday omission does not cause persistent biases in the determination of the day of lunar cycle of the mid-week. The use of a timeseries several years long should average out any yearly biases.

A previous study at Scripps and at other Southern California sites, found that the number of cycles changed from spring to summer, with 1 cycle per lunar cycle in spring and two in summer (Pineda, 1991, 1995), with the coldest waters after a full moon (see also Fig. 1). On the other hand, diatom abundance peaked in spring, and decreased in summer (Fig. 8). To test for highest diatom abundance within the lunar cycle, the coldest days in the lunar cycle corresponding to spring were chosen. This approach included also some of the coldest days in summer and corresponds to the coldest days in spring and summer in the regional average in Fig. 1. Diatom abundance were

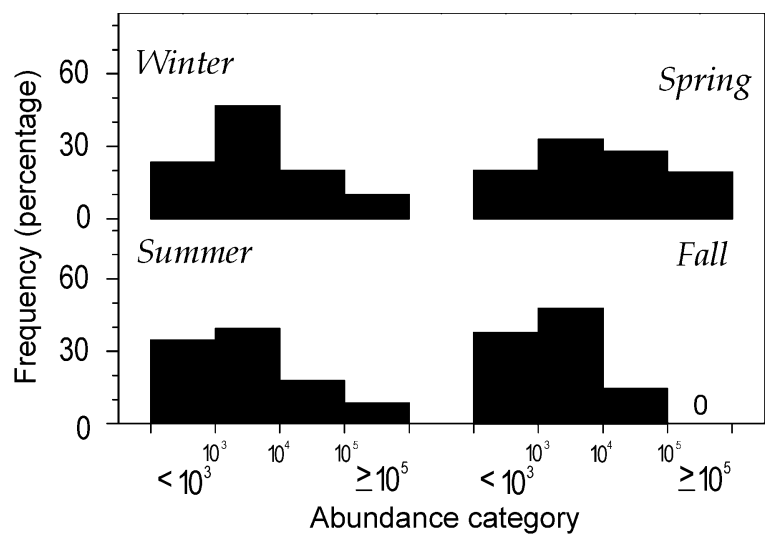

Fig. 8. Seasonal frequency distribution of diatoms, sampled by W.E. Allen at the SIO pier. 


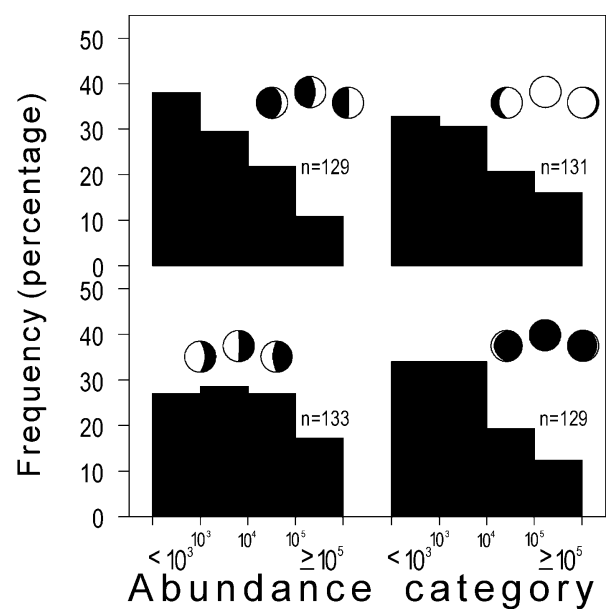

Fig. 9. Abundance frequency distribution of diatoms, sampled by W.E. Allen by groups of lunar cycle days.

grouped a priori into four categories, representing the days of the lunar cycle with more distinctive water-temperature regime in spring: days (a) 3-9 (-o-o), (b) 10-16 (o-○-○), (c) 18-24

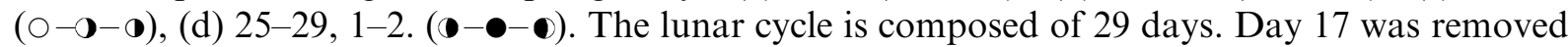
in order to work with four equal lunar-cycle categories (7 days each). The data were further categorised by seasons, because cold water is only predictable in spring and summer; in winter and autumn, anomalies tend to occur randomly within the lunar cycle. Fig. 9 shows that, in spring and summer, frequency distributions of diatoms appears similar in the categories of the lunar cycle 3 9, 10-16, and 25-29, 1-2. However, in lunar cycle days 18-24 ( $-\mathbf{-}-\mathbf{-})$, the frequency distribution appears different. Abundance categories $>10^{5}$ and $10^{4}-10^{5}$ are more frequent than in all other lunar day periods, whilst categories $10^{3}-10^{4}$ and $<10^{3}$ are least common. In winter and autumn, frequency distributions appear similar in all categories (results not shown).

A Mann-Whitney $U$ test was used to determine whether diatom abundance during the coldest days of the lunar cycle $\left(18-24,0_{-}--\right)$were different from the rest of the days $(3-9,10-16$, and 25-29, 1-2) in spring and summer; another test evaluated winter and autumn abundance. In spring and summer, there was evidence of significant difference $(\mathrm{P}<0.05$; one-tailed test; $\left.n_{18-24}=133 ; n_{\text {other days }}=389\right)$. For autumn and winter, there was no evidence of significant differences.

\section{Discussion}

The main aim of this paper is to assess the effect of tidal mixing over the southern California shelf; it is not the intention to reproduce the effect that internal tidal bores may have in this region. For this reason, we use a one-dimensional vertical model, which cannot include internal tidal bores but includes other advective effects, such as the interaction of tidal straining with temperature gradients. The model reproduces the seasonal cycle and several aspects of the fortnightly temperature variability in the SCB, previously attributed to internal tidal bores (Pineda, 1995). 
The model produced cycles in mixing and temperature within the lunar cycle (Figs. 5 and 6), with minima in SST lagging the new (•) and full (○) moon 4.5 and 5 days, respectively (Fig. 7; see below). From these results and previous observations in tidal mixing fronts, it is important to highlight, for future reference, that the maximum effect of bottom tidal stirring is apparent as a decrease in stratification (i.e. temperature) a few days after the maximum tidal currents. In general, we would expect maximum tidal currents at spring tides, so a lag of about 3 days between spring tides and maximum water column mixing (cooling) would be typical (as explained by Sharples and Simpson, 1996).

The model produced more mixing and smaller $\Delta T$ after new ( $\bullet)$ moon than after full moon (O), for 1985 (Fig. 5). From Fig. 5b, we can clearly observe how tidal stirring is greater after a new moon $(\bullet)$ than after a full moon $(\bigcirc)$; this is particularly clear during the spring months. On the other hand, strong mixing after a new moon $(\bullet)$ is not the rule in all years. In other years, such as 1995, stronger mixing is observed after the full moon $(\circ)$, rather than after the new moon $(\bullet)$ (Fig. 6). The model results show also that the number of cycles and the lunar days of maximum mixing change from spring to summer, within a year. This monthly modulation of the stirring and temperature, apparent in Figs. 5 and 6 , is due to the $\mathrm{N}_{2}$ tide. It suggests that the observed 1 cycle in spring-2 cycles in summer in SST anomaly in Southern California stations (Pineda, 1991, 1995) could be related to this process. The $\mathrm{N}_{2}$ monthly tidal modulation works in the same manner as the $S_{2}$ fortnightly tidal modulation. The spring-neap cycle is completed every $\sim 14.75$ days, due to the $\mathrm{M}_{2}-\mathrm{S}_{2}$ frequency difference. In a similar manner, the $\mathrm{N}_{2}$ monthly modulation is 27.62 days, due to the $M_{2}-\mathrm{N}_{2}$ frequency difference. As $\mathrm{N}_{2}$ and $\mathrm{S}_{2}$ are of the same order of magnitude in Southern California, there should be an important monthly variation which, in this case, is manifested as mixing intensification every other spring-neap cycle. Furthermore, $\mathrm{N}_{2}$ varies latitudinally, with maxima in Southern California (Fig. 10); this parallels, somehow, the occurrence or absence of the 1-2 cycle dichotomy in the observations (Pineda, 1995). The dichotomy appears at most stations where $\mathrm{N}_{2}$ is large (Santa Barbara, Santa Monica, Balboa, San Clemente, and La Jolla (SIO)) and disappears where $\mathrm{N}_{2}$ is smaller (Neah Bay, Pacific Grove, and Morro Bay). In Port Hueneme and Oceanside, where $\mathrm{N}_{2}$ is large, there is no clear evidence of the 1-2 cycle dichotomy. It is apparent that the model does not reproduce precisely the 1-2 cycle relative amplitude and occurrence in the observations (e.g. cf. Figs. 1 and 7). This limitation could be related to the fact that the model is forced by a very coarse barotropic tidal model.

The model results suggest that tidal mixing is involved in the fortnightly variability in temperature in the SCB. Since bottom tidal mixing could produce directly drops in SST, by mixing the water column from bottom to surface, and tidal mixing varies with the phase of the moon, this would produce lunar variability in sea-surface temperature. However, to our knowledge, a direct relationship between surface water temperature and bottom tidal mixing has never been reported in the SCB. The fact that there is a lag of 3 days between the observed and predicted temperature minimum suggests that other processes, such as internal tides or waves, might be involved. This observation suggests that tidal mixing may somehow modulate the internal tidal bores, to produce the observed fortnightly periodicity. Field observations are required, however, to test this hypothesis.

The model shows strong semi-diurnal variability $\left(2{ }^{\circ} \mathrm{C}\right.$, Fig. 11$)$ in temperature during August and September; this is due to the interaction of tidal straining with the horizontal temperature gradients. It falls short of that observed by Pineda (1994), with values of about $7^{\circ} \mathrm{C}$, which can be 


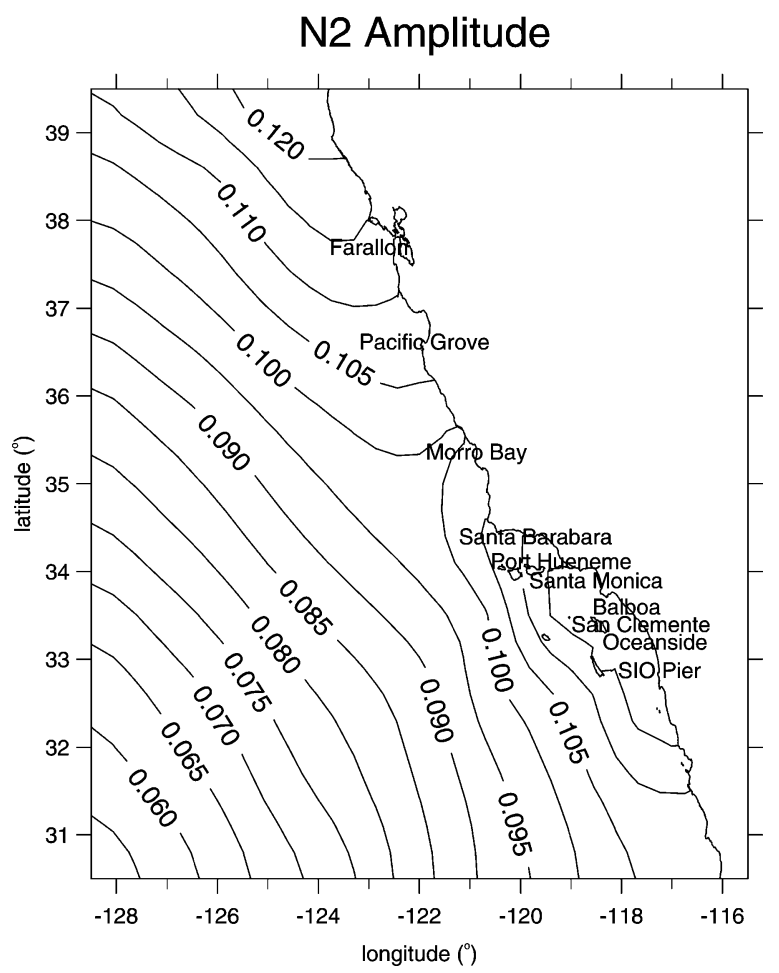

Fig. 10. Amplitude of the $\mathrm{N}_{2}$ tidal component of elevation for the Southern California Bight, using Schwiderski (1980) data.

explained either by the underestimation of the magnitude of the temperature gradients or more probably by the inability to reproduce the observed internal tidal bores (Cairns, 1967; Winant, 1974; Pineda, 1991, 1994, 1995). Although the model is able to produce offshore currents of the order of $10 \mathrm{~cm} \mathrm{~s}^{-1}$ (Fig. 11b), it is not able to reproduce the energetic two-way currents observed by Pineda $(1994,1999)$; this is, again, because the model is not able to reproduce the internal motions.

Changes in fortnightly bottom mixing, associated with the spring-neaps cycle, may produce changes in the light and nutrient environment; these may then affect phytoplankton abundance (discussed in Demers et al., 1986). Diatom abundance was highest in spring and summer, as has been observed before (e.g. Allen, 1941) and on days 18-24 (O-O-O). of the lunar cycle, although the differences in abundance within the lunar cycle appear small. Tynan (1993) observed increased diatom abundance associated with internal tidal bores in daily time-series. An increase in diatom abundance could be explained: (1) as a growth response to the increased availability of nutrients due to mixing, either from bottom stirring or internal wave mixing (Cullen et al., 1983; Demers et al., 1986; Tynan, 1993; Simpson et al., 1994); (2) by the advection of diatoms from subsurface, deeper, sub-thermocline waters towards the shallow Scripps Pier(the same argument used by Pineda $(1991,1994,1999)$ to explain the onshore transport of invertebrate and fish larvae by internal tidal bores); and (3) by a combination of (1) and (2). Our data do not allow us to distinguish between the different hypotheses. 

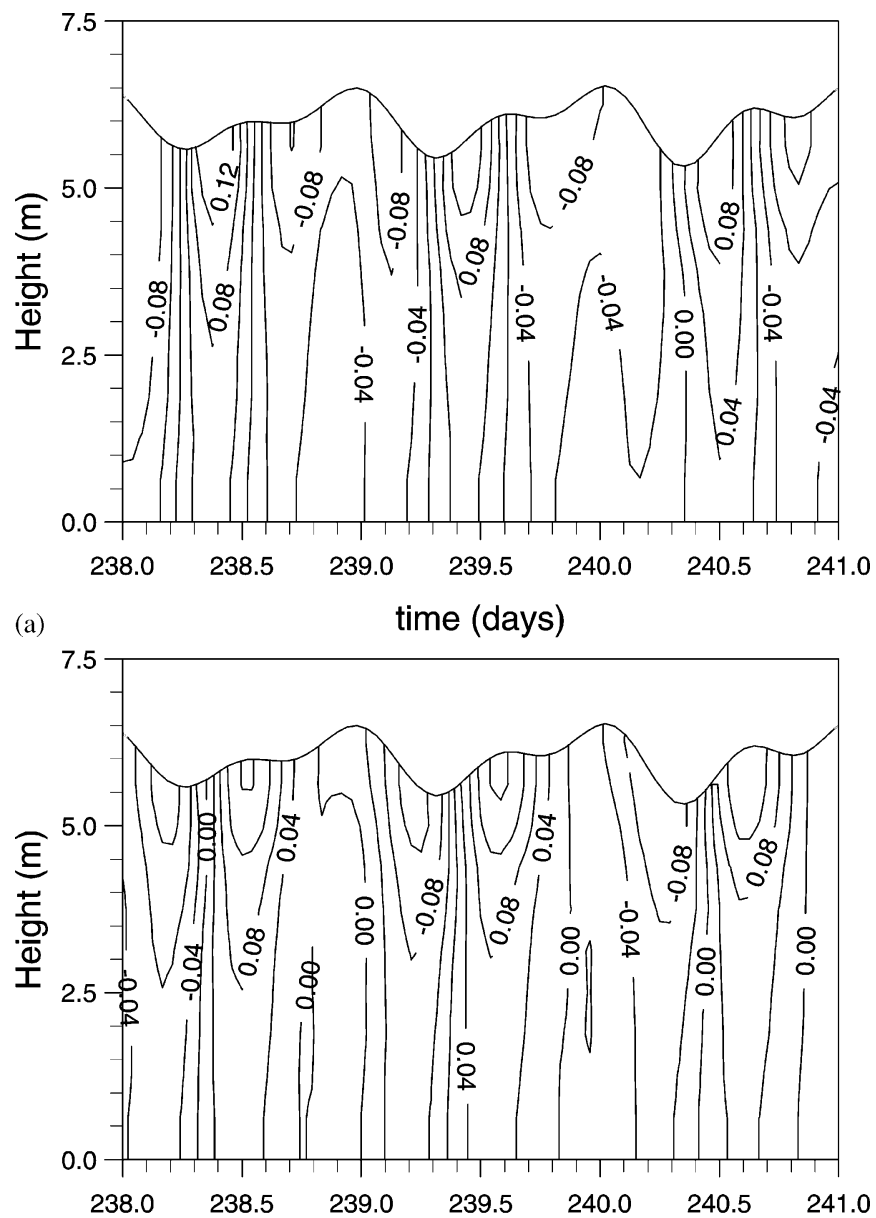

(b) time (days)

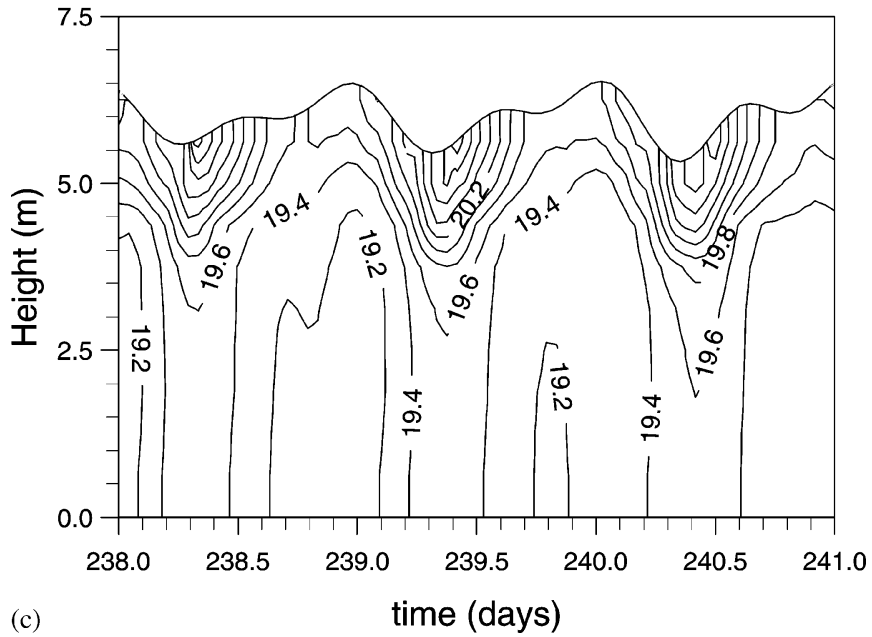

Fig. 11. Simulation of semi-diurnal variability in a point near SIO Pier: (a) north-south velocities; (b) east-west velocities; and (c) temperature. 


\section{Conclusion}

Whilst the model is one-dimensional, it has achieved its purpose of reproducing some of the aspects of the seasonal and fortnightly variability in temperature; this suggests bottom tidal mixing as an important process controlling the water temperatures of the area. Nevertheless, the fact that there is a lag of 2-3 days between observations and predictions suggests that other processes might be involved. The occurrence of internal tidal bores in this area (Pineda, 1995) makes them a strong candidate for the extra source of mixing. Our results suggest an effect of bottom mixing on diatom abundance, either directly through vertical mixing and injection of nutrients to the surface layer, or indirectly, by modulating the internal bores and enhancing internal wave mixing and shoreward transport. Field observations and a two-dimensional model may be required, to elucidate the precise mechanisms of modulation of temperature and diatom abundance by barotropic tidal mixing.

\section{Acknowledgements}

The authors thank Ms. P. Habziabdic for proof-reading the latest version of the manuscript. AS thanks Dr. Bethan Jones for facilitating the climatological and tidal data. A portion of this manuscript is based upon JP.'s thesis dissertation, at the Scripps Institution of Oceanography. JP thanks the Committee Members for reading some of the material, the SIO for providing temperature data and the US National Science Foundation for support. This is a Woods Hole Oceanographic Institution Contribution, No. 9872.

\section{References}

Allen, W.E., 1927. Quantitative studies on inshore marine diatoms and dinoflagellates of southern California in 1921. Bulletin of the Scripps Institution of Oceanography 1, 19-29.

Allen, W.E., 1930. Methods in quantitative research of marine microplankton. Bulletin of the Scripps Institution of Oceanography 2, 319-329.

Allen, W.E., 1941. Twenty years' statistical studies of marine plankton dinoflagellates of Southern California. The American Midland Naturalist 26, 603-635.

Balch, W.M., 1986. Are red tides correlated to spring-neap tidal mixing?: use of a historical record to test mechanisms responsible for dinoflagellate blooms. In: Bowman, M.J., Yentsch, C.M., Peterson, W.T. (Eds.), Tidal Mixing and Plankton Dynamics. Springer, Berlin, pp. 193-223.

Berliand, T., 1960. Metodika climatologicheskih raschetov radiatsii. Meteorologia i Hydrologia 6, 9-16.

Cairns, J.L., 1967. Asymmetry of internal tidal waves in shallow coastal waters. Journal of Geophysical Research 72 , 3563-3565.

Cullen, J.J., Stewart, E., Renger, E., Eppley, R.W., Winant, C.D., 1983. Vertical motion of the thermocline, nitracline, and chlorophyll maximum layers in relation to currents on the Southern California shelf. Journal of Marine Research 41, 239-262.

Demers, S., Legendre, L., Therriault, J.-C., 1986. Phytoplankton responses to vertical tidal mixing. In: Bowman, M.J., Yentsch, C.M., Peterson, W.T. (Eds.), Tidal Mixing and Plankton Dynamics. Springer, Berlin, pp. 1-40.

Edinger, J.E., Dutweilerand, D.W., Geyer, J.C., 1968. The response of water temperatures to meteorological conditions. Water Resources Research 4, 1137-1145. 
Haury, L.R., McGowan, J.A., Wiebe, P.H., 1978. Patterns and processes in the time-space scale of plankton distribution. In: Steele, J.H. (Ed.), Spatial Patterns in Plankton Communities. Plenum Press, New York, pp. 277-327.

Leichter, J.J., Shellenbarger, G., Genovese, S.J., Wing, S.L., 1998. Breaking internal waves on a Florida coral reef: a plankton pump at work? Marine Ecology Progress Series 166, 83-97.

Mellor, G.L., Yamada, T., 1982. Development of a turbulence closure model for geophysical fluid problems. Reviews in Geophysics and Space Physics 20, 851-875.

Pineda, J., 1991. Predictable upwelling and the shoreward transport of planktonic larvae by internal tidal bores. Science (Washington DC) 253, 548-551.

Pineda, J., 1994. Internal tidal bores in the nearshore: warm-water fronts, seaward gravity currents and the onshore transport of neustonic larvae. Journal of Marine Research 52, 427-458.

Pineda, J., 1995. An internal tidal bore regime at nearshore stations along western USA: predictable upwelling within the lunar cycle. Continental Shelf Research 15, 1023-1041.

Pineda, J., 1999. Circulation and larval distribution in internal tidal bore warm fronts. Limnology and Oceanography 44, 1400-1414.

Pugh, D.T., 1987. Tides, Surges and Mean Sea-Level. Wiley, Chichester, 472pp.

Schwiderski, E.W., 1980. NSWC Ocean Tide Data Tape, GOTD 1980 Report No. Naval Surface Weapons Center, Dahlgren, VA 22448, USA.

Scripps-Institution-of-Oceanography, 1989. Surface water temperatures, salinities, and densities at shore stations. United States West Coast. 1988. SIO Reference Series Report No. SIO 89-9, Scripps Institution of Oceanography, University of California.

Sharples, J., Simpson, J.H., 1996. The influence of spring-neaps cycle on the position of shelf sea fronts. In: Aubrey, D.G., Friedrichs, C.T. (Eds.), Buoyancy Effects on Coastal and Estuarine Dynamics, Vol. 53. AGU, Washington, DC, pp. 71-82.

Simpson, J.H., Bowers, D., 1981. Models of stratification and frontal movement in the shelf seas. Deep-Sea Research $28,727-738$.

Simpson, J.H., Brown, J., Matthews, J., Allen, G., 1990. Tidal straining, density currents and stirring in the control of estuarine stratification. Estuaries 13, 125-132.

Simpson, J.H., Sharples, J., 1992. Dynamically-active models in prediction of estuarine stratification. In: Prandle, D. (Ed.), Dynamics and Exchange in Estuaries and Coastal Zone, Vol. 40. AGU, Washington, DC, pp 101-113.

Simpson, J.H., Souza, A.J., Lavin, M.F., 1994. Tidal mixing in the Gulf of California. In: Beven, K.J., Chatwin, P.C., Millbank, J.H. (Eds.), Mixing and Transport in the Environment. Wiley,, Chichester, pp. 169-182.

Tont, S.A., 1986. W.E. Allen's 20 year phytoplankton collection, Vol. 1 - diatoms. IMR Reference Report no. 86-3, Scripps Institution of Oceanography.

Tynan, C., 1993. The effects of small-scale turbulence on dinoflagellates. Ph.D. Thesis, University of California, San Diego.

United-States-Navy, 1992. Marine Climatic Atlas of the World Report No. Naval Oceanography Command Detachment, 200MB, CD-ROM.

Winant, C.D., 1974. Internal surges in coastal waters. Journal of Geophysical Research 79, 4523-4526. 